\title{
Erratum to: Regional lymph node metastasis and locoregional recurrence of rectal carcinoma in the era of TNM surgery. Implications for treatment decisions
}

Paul Hermanek • Susanne Merkel • Rainer Fietkau •

Claus Rödel • Werner Hohenberger

Published online: 6 April 2010

(C) Springer-Verlag 2010

\section{Erratum to: Int J Colorectal Dis}

DOI 10.1007/s00384-009-0864-2

The original version of this article unfortunately contained a mistake. The title was incorrect. The title should be "Regional lymph node metastasis and locoregional recurrence of rectal carcinoma in the era of TME surgery. Implications for treatment decisions".

The online version of the original article can be found at http://dx.doi. org/10.1007/s00384-009-0864-2.

P. Hermanek $\cdot$ S. Merkel $(\bowtie) \cdot$ W. Hohenberger Department of Surgery, University Hospital,

Krankenhausstr. 12,

91054 Erlangen, Germany

e-mail: susanne.merkel@uk-erlangen.de

R. Fietkau

Department of Radiotherapy, University Hospital,

Erlangen, Germany

C. Rödel

Department of Radiotherapy and Oncology, University Hospital, Frankfurt/Main, Germany 